\title{
Family Meal- and Related-Practices in Families of Preschoolers: Differences by Family Income
}

\author{
Emily E. Nowlin, John Worobey*, Harriet S. Worobey \\ Department of Nutritional Sciences, School of Environmental and Biological Sciences, Rutgers University, \\ New Jersey, USA \\ Email: $\underline{\text { worobey@rci.rutgers.edu }}$
}

Received 15 December 2014; accepted 9 April 2015; published 10 April 2015

Copyright (C) 2015 by authors and Scientific Research Publishing Inc.

This work is licensed under the Creative Commons Attribution International License (CC BY). http://creativecommons.org/licenses/by/4.0/

(c) (i) Open Access

\section{Abstract}

The present study asked parents of preschool-aged children from differing socioeconomic groups to complete a questionnaire regarding the frequency of specific behaviors that comprise the food environment. Participants were 94 mothers of preschool-age children who attended either Day Care (middle-income) or Head Start (low-income) programs. Many of the items tested showed similar characteristics for the food environment between the Head Start and Day Care centers, including the frequency that children were involved in meal preparation, the frequency that children were encouraged to finish the food on their plate, the frequency that a parent ate a meal at the table with the child, and the frequency of opportunities to try foods that the parents disliked themselves. Relative to the Head Start children, however, children attending Day Care were more restricted from eating desserts and salty snacks, more encouraged to try new foods, and more often consumed breakfast. Aside from characteristics of the food environment, children in Day Care spent more minutes in outdoor play and slept nearly an hour more each night, while those who attended Head Start spent more time watching television and playing video games. It is recommended that families make a better effort to create an optimal food environment for their children.

\section{Keywords}

Family Meals, Food Environment, Preschool Children

\section{Introduction}

As primary socializing agents, parents play an important role in the development of their children's obesogenic Corresponding author. 
behaviors related to eating, physical activity, and use of screen media (Patrick, Hennessy, McSpadden, \& Oh, 2013). In short, they are responsible for raising and feeding their children, educating their children about nutrition, and providing the food available for their children to consume. The food environment they provide should expose children to new foods on numerous occasions and allow them to choose some of their own food, practices that have been shown to encourage healthy eating (Benton, 2004). It should also incorporate nutrition education and involve children in meal preparation. Such efforts should be implemented during a young age because weight problems that develop early in life are likely to persist (Jansen et al., 2012).

A healthy food environment includes the quality of food that is offered, the opportunity for sampling a variety of foods, and the frequency of family meals (Story, Kaphingst, Robinson-O’Brien, \& Glanz, 2007). While a family meal may take many forms, researchers generally define family meals as "those occasions when food is eaten simultaneously in the same location by more than 1 family member” (Martin-Biggers et al., 2014: p. 236). Interestingly, a number of experts have suggested that one contributor to child obesity has been the decline in the frequency of family meals (McIntosh, 1999; Taveras et al., 2005), but associations between family meals and weight outcomes are mixed (Fulkerson, Larson, Horning, \& Neumark-Sztainer, 2014). Although research on family meals has sparked recent interest, surprisingly little work has been conducted on low-income families, but what does exist suggests that fewer meals are shared in lower-income families relative to higher socioeconomic households (Neumark-Sztainer, Hannan, Story, Croll, \& Perry, 2003).

When family meals occur at least three times per week, children are more likely to be in the normal weight range and have healthy dietary habits than those who eat fewer than three meals together (Hammons \& Fiese, 2011). Indeed, Anderson and Whitaker (2010) reported that preschool children who ate family meals at least five or more evenings per week were at a $16 \%$ decreased risk of obesity compared to those who had fewer family meals together. Families with children of healthy weights consider family mealtimes a priority and use this time to engage in frequent and positive communication, as compared to families with a child who is overweight or obese (Fiese, Hammons, \& Grigsby-Toussaint, 2012). However, if there is arguing, accusing, or yelling at the family table, it can be an aversive experience for the family and even affect child energy intake (Burnier, Dubois, \& Girard, 2011).

An increased frequency of family meals also decreases the frequency of the alternative; that is, eating meals alone in front of the television. Avoiding meals in front of the television is beneficial in that it prevents the mindless, excessive consumption of junk food (Moray, Fu, Brill, \& Mayoral, 2007). Also, family meals can provide the child with exposure to healthier foods such as fruits and vegetables, and the increased frequency of family meals provides the child with many opportunities to try these foods (Christian, Evans, Hancock, Nyjkaer, \& Cade, 2013).

In addition to the influence of the family meal itself, a parent's feeding style or use of control during meals may impact the child's eating behavior either positively or negatively. Some parents exert control through the use of restriction and force. In the context of feeding, high control has been associated with the lower availability and intake of fruit juices and vegetables (Patrick, Nicklas, Hughes, \& Morales, 2005). In addition, when highly palatable foods are restricted, the desire for those foods can go up, causing the children to over-indulge on these foods when given the opportunity, even in the absence of hunger (Fisher \& Birch, 2002). Despite good intentions then, restricting unhealthy food choices may therefore backfire. It is also counterproductive when parents try to control how much the child eats by pressuring the child to eat more. When the amount of food children consume is based on how much they are told to eat, children learn to ignore the signals from their own bodies, and lose the ability to self-regulate their caloric intake. For example, in a study where preschool-aged children drank either a caloric or non-caloric beverage before consuming a test meal, the children of parents who were less controlling were better able to adjust their caloric intake to compensate for the preload (Evers, 1997).

In a study of Latino families with 5 - 7-year-old, Arredondo et al. (2006) found that parental discipline was not associated with children's healthy eating or physical activity; however, higher parental control was positively related to children's unhealthy eating. Hughes et al. (2006) found low-income Hispanic parents to report more parent-centered/high control feeding strategies as compared to low-income African-American parents, while Worobey, Borelli, Espinosa and Worobey (2013) found low-income Hispanic mothers to be higher in restriction and pressuring to eat relative to middle-income white mothers, with the Hispanic children at higher weight. Some research has shown lower-income African-American mothers to score higher than higher-income white mothers on restriction and pressuring to eat (Spruijt-Metz, Lindquist, Birch, Fisher, \& Goran, 2002), but other work shows a more complex association between feeding style and child weight. That is, Powers, Chamberlin, 
van Schaick, Sherman and Whitaker (2006) found that higher pressuring to eat by low-income African-American mothers was associated with lower body-mass index in their preschool-age children, but no comparison racial/ethnic group was included. Use of pressure as a feeding practice may be a function of a family's socioeconomic status or ethnicity, as Baughcum et al. (2001) found that low-income families reported significantly higher use of pressure compared to high-income families, and Brown, Ogden, Vögele and Gibson (2008) found that non-white families were significantly more likely to use pressure compared to white families.

Based on the studies presented above, family mealtimes would thus appear to be a differentiating factor between families who have children of normal weight and those who have children who are overweight or obese. With respect to minority families, however, little is known about family meals or their food environments. A recent study found that, relative to African-American families, Hispanic families with preschool-age children ate family meals more often, and were less likely to eat in front of the television (Skala et al., 2012). Interestingly, Andaya, Arredondo, Alcaraz, Lindsay and Elder (2011) reported that Latino children who ate breakfast as a family had an increased intake of fruit and vegetables, while eating away from the television provided greater benefits due to decreased consumption of junk food and soda. These results suggest that the family meal need not refer exclusively to dinner. However, minority status in the Andaya et al. (2011) study may have been confounded with low income, as is apparent in the work on feeding styles (Baughcum et al., 2001; Powers et al., 2006; Worobey et al., 2013).

This point is aptly illustrated by Varela et al. (2004) who examined parenting (though not feeding) styles across Mexican, Mexican-American, and Caucasian families. Their results indicated that Mexican-American parents demonstrated a variety of parenting styles, but that the socioeconomic factors associated with minority status such as low education and income level, rather than their affiliation to Mexican culture, may have instead accounted for their use of an overly controlling style. While the above studies suggest that feeding styles may differ by socioeconomic status, the fact remains that relatively little research has examined family meals in low-income families (Koszewski, Behrends, Nichol, Sehi, \& Jones, 2011; Neumark-Sztainer et al., 2003), with studies of preschool families primarily confined to dinnertime structure or conversation (Dreyer \& Dreyer, 1973; Feiring \& Lewis, 1987).

The present study was therefore an exploratory attempt at comparing differences in the food environments of low-income families and middle-income families. To accomplish this, parents whose children attended either full-day Head Start programs (representing low-income families) or private Day Care centers (representing middle-income families) were asked to participate. As little is known with respect to the mealtime routines of families with preschoolers, formal hypotheses were not posed. However, since income usually co-varies with education in determining socioeconomic status (Liberatos, Link, \& Kelsey, 1988), it was expected that the middle-income families would report feeding practices more in line with a less controlling style (e.g., less pressuring) and better nutrition (e.g., eating breakfast), as well as encouraging physical activity (e.g., less TV watching).

\section{Methods}

\subsection{Participants}

Participants in this study were 94 mothers of preschool-age children who attended either Day Care or Head Start programs in the central New Jersey area [For ease of presentation, we will hereafter refer to the two groups of mothers/children as Day Care and Head Start throughout this report, though we consider middle-versus low-income status to be the discriminating variable]. The Day Care centers were independent not-for-profit programs, charging tuition for the children's attendance and offering half- or full-day care. As such, the mothers ( $\mathrm{N}=47)$ whose children were enrolled in the day care programs comprised the middle-income group. These mothers were an average age of 36 years (SD $=5$ years) with the modal mother having some graduate schooling. Within this group, 31 self-identified as being Caucasian, nine as East Asian, two as Hispanic, one as African-American, and four as Other/Not specified. In contrast, the Head Start programs enrolled children whose family household income could not exceed 133\% of the federal poverty level. For example, the 2013 New Jersey annual income limit for a family of three for Head Start eligibility was \$24,817 (New Jersey Head Start, 2014). The Head Start mothers $(\mathrm{N}=47)$ comprised the low-income group, averaged 31 years of age $(\mathrm{SD}=6)$, and most had completed high school. Unlike the middle-income mothers, none of the mothers in this group self-identified as Caucasian or East Asian. Instead, 42 self-reported themselves as Hispanic, three as African-American, and two as Other/Not specified. As relayed by the Head Start directors, most of the children in their centers were Mexican- 
American.

\subsection{Instrument}

A 3-page questionnaire on the family food environment was designed specifically for the present study, and consisted of 18 questions regarding meal-related and some non-meal related variables, along with a few items that covered demographic information. Brief instructions for completing the questionnaire appeared on the first page. The meal-related variables covered the children's role in grocery shopping, their involvement in meal preparation, their eating meals with a parent, their being pressured to eat, etc. The non-meal related variables asked about time spent on television/video games, outdoor physical activity, and sleep. Both English and Spanish versions of the questionnaire were prepared and distributed. For the meal-related questions, responses were rated using a scale where $0=$ "Never (Nunca)," 1 = "Sometimes (A veces)," 2 = "Often (Frecuentemente)," $3=$ "Usually (Normalmente)," and 4 = "Always (Siempre)."

\subsection{Procedure}

Directors of five Day Care centers and two Head Start centers in proximity to the university were contacted and asked to participate in the study. Approval from the university's Institutional Review Board for the survey instrument was obtained prior to the study's onset. In the first week of October, 2012, the survey was distributed by the program directors to the parents of 4-year-old children enrolled at their centers, with the surveys returned to the directors up through mid-December.

Of the 117 surveys distributed to the Day Care center parents, 47 were returned for a response rate of $40 \%$. Coincidentally, of the 57 surveys distributed to Head Start parents, 47 were also returned for a response rate of $83 \%$. Although the questionnaires were addressed as "Dear Parents," all returned surveys had been completed by mothers. Mothers of boys and girls were near equal in participation across type of programs (24 boys, 23 girls in Day Care; 23 boys and 23 girls in Head Start, with one child's gender not specified). Of the Day Care mothers, approximately $28 \%$ reported themselves as "stay at home parent;" of the Head Start mothers the figure was about 32\%. Although the questionnaire asked for children's heights and weights, only two Head Start parents provided that information. For the Day Care children, however, BMI for age and sex could be computed for the group, and the children were at the $58^{\text {th }}$ percentile.

\section{Results}

Data for the 94 surveys were entered into an SPSS 20.0 (IBM Corporation, Armonk, NY) spreadsheet, with mean scores computed for each variable. As the questionnaire was created specifically for this study, reliability and validity information is not available. However, to determine internal consistency, Cronbach's alpha was computed using the 10 items that reflected optimal practices. The reliability coefficient of .759 suggests an acceptable level of internal consistency. $T$-tests were then conducted to determine if differences existed between the two groups.

As shown in the Table 1, four of 15 of the food and meal-related items on the survey were significantly different between groups. Sweets and salty snacks were restricted by Day Care mothers more often than by Head Start mothers, although the latter obviously did occasional restricting (Recall that ratings of 1,2 , and 3 , respectively, represented "sometimes," "often," and "usually"). Day Care mothers usually encouraged their children to try new foods, while Head Start mothers did so a little more than often. Head Start mothers admitted to more frequently preparing a special food just for their child, although both groups rated this less than often. Head Start children usually ate breakfast, but the children attending Day Care nearly always ate breakfast.

In terms of best practices that were not meal-related, Head Start children reportedly spent about 35 minutes more each day watching television or playing with video games. Day Care children averaged nearly an hour more of outside play each day, as well as an hour more of sleep each night.

\section{Discussion}

Frequent family meals can provide the opportunity for parents to discuss nutrition and the importance of healthy eating with their children. Our results indicate that both the low- and middle-income families of this study regularly engaged in family meals, as both the Head Start and Day Care mothers reported that they or their spouse 
Table 1. Family meals- and related-items by center type.

\begin{tabular}{|c|c|c|c|}
\hline & Day Care & Head Start & \\
\hline & $M(S D)$ & $M(S D)$ & $t$-value \\
\hline \multicolumn{4}{|l|}{ Pre-meal practices-frequencey that: } \\
\hline Child goes along to grocery store & $2.74(0.97)$ & $2.78(1.02)-0.16$ & -0.16 \\
\hline Child gets to choose some groceries & $\begin{array}{c}1.98(1.03) 2.38 \\
(1.28)-1.69\end{array}$ & $2.38(1.28)$ & -1.69 \\
\hline Chid helps in meal preparation & $1.93(1.04)$ & $1.89(1.30$ & 0.19 \\
\hline \multicolumn{4}{|l|}{ Family meal practices-Frequency that: } \\
\hline Child is pressured to finish entire plate & $2.36(1.48)$ & $2.80(1.37)$ & -1.49 \\
\hline Child must finish vegetables before dessert & $2.77(1.22)$ & $2.67(1.25)$ & 0.36 \\
\hline Sweets and salty snacks ae restriced & $2.45(1.04)$ & $1.89(1.05)$ & $2.57^{* *}$ \\
\hline \multicolumn{4}{|l|}{ Nutrition considerations-Frequency that: } \\
\hline MyPlate Guidelines are followed & $2.07(1.42)$ & $2.20(1.17)$ & -0.44 \\
\hline Reasons are given for serving certain foods & $2.38(1.15)$ & $2.49(1.25)$ & -0.42 \\
\hline Child is encouraged to try new foods & $3.06(0.96)$ & $2.35(1.25)$ & $3.09^{* *}$ \\
\hline \multicolumn{4}{|l|}{ Shared family meal-Frequency that: } \\
\hline Child eats same meal as rest of family & $3.11(1.03)$ & $2.96(1.16)$ & 0.66 \\
\hline Child eats a meal with parent at table & $3.19(0.97)$ & $3.09(1.06)$ & 0.51 \\
\hline Preferred food is prepared just for child & $1.17(1.07)$ & $1.87(1.24)$ & $-2.89^{*}$ \\
\hline \multicolumn{4}{|l|}{ Best practices-Meals-Frequency that: } \\
\hline Child eats breakfast & $3.80(0.54)$ & $3.17(1.11)$ & $3.49^{* * *}$ \\
\hline Child eats in front of television & $0.98(1.07)$ & $1.07(0.86)$ & -0.43 \\
\hline Chid eats with family in restaurants & $1.51(0.83)$ & $1.36(0.80)$ & 0.91 \\
\hline \multicolumn{4}{|l|}{ Best practices-Other-Number of hours that: } \\
\hline Child spent on TV/video games daily & $1.651 .06)$ & $2.23(1.25)$ & $-2.42^{*}$ \\
\hline Child plays out of doors each day & $2.56(0.79)$ & $1.66(1.38)$ & $3.89^{* * * *}$ \\
\hline Child sleeps each night & $9.74(0.70)$ & 8.77 (1.19) & $4.73^{* * *}$ \\
\hline
\end{tabular}

${ }^{*} p<0.05,{ }^{* *} p<0.01,{ }^{* * *} p<0.001$.

usually ate with their child. Despite some statistically significant differences between the feeding practices of the two groups, the middle- and low-income mothers were indistinguishable on the majority of items. Pre-meal practices such as having their children help with grocery shopping and meal preparation, as well as moderately pressuring their children to eat were equivalent across groups. MyPlate Guidelines were often followed by the two groups of mothers, and reasons for serving certain foods were just as likely to be given by both. [MyPlate (and the Spanish version MiPlato) is the current visual that emphasizes a meal of fruit, vegetable, grain, protein, and dairy groups (USDA, 2011)]. This finding suggests that lower socioeconomic status should not presuppose a family's lack of adherence to optimal mealtime practices.

Although pressuring to eat was similar across groups, mothers of the Day Care children more often restricted sweets and salty snacks for their children than did the mothers of Head Start children. Restricting foods as a type of control is more often seen in low-income parents and as it pertains to savory snacks is a healthier feeding practice. Ironically, research shows that restricting a young child's diet is correlated with eating in the absence of hunger and increased difficulty regulating his or her food intake (Fisher \& Birch, 2002; Hill et al., 2008). Thus, giving children the opportunity to eat "forbidden foods" without restriction may more likely lead to moderation with a variety of foods. As the Day Care children were predominantly at healthy weights as gleaned from their BMIs-for-age, it does not appear that maternal restriction had led to their overeating, at least at this young age. While the efficacy of restriction may be questioned, the greater encouragement of their children to try new foods by the Day Care mothers was a behavior that is undeniably optimal. 
Given their limited resources, one might have predicted that the Head Start mothers would be less inclined to prepare (apart from allergy reasons) a particular food just to appease the child. However, relative to the Day Care mothers the Head Start mothers indicated that they did this more often. Some research has found low-income Hispanic mothers of preschool children to be more indulgent in their feeding style (Hughes, Shewchuk, Baskin, Nicklas, \& Qu, 2008). However, as a component of parental indulgence is responsiveness (Hughes et al., 2006), this should not be deemed a liability. As most of the Head Start families of this study were Hispanic as well, our results provide some replication for that finding, although the link they established with child overweight could not be examined here.

In terms of overall best practices, the Day Care children appeared to fare somewhat better than the Head Start children. For example, breakfast was eaten more regularly by the Day Care children than the Head Start children. While long linked to better school performance (Murphy, 2007), children who eat breakfast regularly have been found to eat more fruits and vegetables (Andaya et al., 2011) and to be at lower risk for overweight (Affenito et al., 2005). Although both groups of children only infrequently ate while watching television, the Head Start children averaged more than two hours of screen time each day while the Day Care children averaged less than two hours. Because of the risk for attention problems, school difficulties, sleep disorders, and obesity associated with excess use of entertainment media, the American Academy of Pediatrics (AAP, 2013) recommends that screen time be limited to less than two hours per day. The higher average for the Head Start children obviously exceeded this amount, but given nationwide estimates of children engaged with entertainment media for 7 hours per day, their level of screen time is not alarming.

In the fight against childhood obesity, the American Academy of Pediatrics (AAP, 2006) has also published recommendations for physical activity for children, that is, 60 minutes or more per day. Although the AAP does not specify outdoor play per se, their suggested activities for preschoolers include running, tumbling, throwing, and catching, which are more outdoor than indoor pursuits. Despite the near hour difference between the Day Care and Head Start children, both groups did average more than a full hour of outside play, again suggesting adequate adherence to the AAP recommendations. With regard to sleep, however, both groups of children fell short of recommendations for their age. For children ages 3 - 5 years, the Centers for Disease Control and Prevention (2012) recommend 11 - 13 hours of sleep each night; although they recognize that individual children's sleep needs may vary. Recent research suggests that insufficient sleep in children may influence hypothalamic functioning, which can adversely affect appetite and the expenditure of energy (Taheri, 2006). Even though the Day Care children reportedly got more sleep than the Head Start children, both groups would appear in need of increasing their amount of sleep.

A number of limitations to this study must be acknowledged. Despite the evenness in number of the two groups of mother-child dyads, their different racial/ethnic composition as well as their educational levels presents a confound to income as the explanatory variable; however, this weakness may be a standard criticism of studies that explore the impact of socioeconomic status on maternal behavior (Baughcum et al., 2001; Powers et al., 2006; Worobey et al., 2013). Another weakness lies in the unavailability of BMI data for the Head Start children. Although the two children for whom height and weight were reported were at the $99^{\text {th }}$ percentile for age and sex, it would be an overreach to assume that the Head Start low-income group weighed significantly more than the Day Care children, or that the food environment was responsible. Finally, while the two groups were equal in size, the discrepant response rate displayed by the Day Care versus Head Start mothers is a further weakness.

Based on these results, however, it is suggested that parents make an effort to create an ideal home food environment for children. Such an environment should give children more opportunity to choose what and how much to eat. Parents should also encourage their children to eat breakfast frequently but minimize pressuring them to eat or finishing the food on their plates. Families should make an effort to eat together frequently and expose children to new foods frequently and repetitively, including foods that the parents may not like, incorporate the child's food preferences in the diet often, provide opportunities for children to be involved in meal preparation, and educate children about nutrition and its importance.

\section{Acknowledgements}

The authors wish to thank the Head Start and Day Care Center directors who facilitated our survey distribution: Cheryl Devine, Audrey Kowalski, Dorothy Lamar, Donna Lambdin, Jennifer Manuola, and Michelle Rodriguez; as well as the mothers who completed the surveys. 


\section{References}

Affenito, S. G., Thompson, D. R., Barton, B. A., Franko, D. L., Daniels, S. R., Obarzanek, E., Schreiber, G. B., \& Striegel-Moore, R. H. (2005). Breakfast Consumption by African-American and White Adolescent Girls Correlates Positively with Calcium and Fiber Intake and Negatively with Body Mass Index. Journal of the American Dietetic Association, 105, 938-945. http://dx.doi.org/10.1016/j.jada.2005.03.003

American Academy of Pediatrics (2006). Active Healthy Living: Prevention of Childhood Obesity through Increased Physical Activity. Pediatrics, 117, 1834. http://dx.doi.org/10.1542/peds.2006-0472

American Academy of Pediatrics (2013). Media and Children.

http://www.aap.org/en-us/advocacy-and-policy/aap-health-initiatives/Pages/Media-and-Children.aspx

Andaya, A. A., Arredondo, E. M., Alcaraz, J. E., Lindsay, S. P., \& Elder, J. P. (2011). The Association between Family Meals, TV Viewing during Meals, and Fruit and Vegetables and Soda and Chips Intake among Latino Children. Journal of Nutrition Education and Behavior, 43, 308-315.

Anderson, S. E., \& Whitaker, R. C. (2010). Household Routines and Obesity in US Preschool-Aged Children. Pediatrics, 125, 420-428. http://dx.doi.org/10.1542/peds.2009-0417

Arredondo, E. M., Elder, J. P., Ayala, G. X., Campbell, N., Baquero, B., \& Duerksen, S. (2006). Is Parenting Style Related to Children's Healthy Eating and Physical Activity in Latino Families? Health Education Research, 21, 862-871. http://dx.doi.org/10.1093/her/cyl110

Baughcum, A. E., Powers, S. W., Johnson, S. B., Chamberlain, L. A., Deeks, C. M., Jain, A., \& Whitaker, R. C. (2001). Maternal Feeding Practices and Beliefs and Their Relationships to Overweight in Early Childhood. Journal of Developmental \& Behavioral Pediatrics, 22, 391-408. http://dx.doi.org/10.1097/00004703-200112000-00007

Benton, D. (2004). Role of Parents in the Determination of the Food Preferences of Children and the Development of Obesity. International Journal of Obesity, 28, 858-869. http://dx.doi.org/10.1038/sj.ijo.0802532

Brown, K. A., Ogden, J., Vögele, C., \& Gibson, E. L. (2008). The Role of Parental Control Practices in Explaining Children's Diet and BMI. Appetite, 50, 252-259. http://dx.doi.org/10.1016/j.appet.2007.07.010

Burnier, D., Dubois, L., \& Girard, M. (2011). Arguments at Mealtime and Child Energy Intake. Journal of Nutrition Education \& Behavior, 43, 473-481. http://dx.doi.org/10.1016/j.jneb.2011.01.005

Centers for Disease Control and Prevention (2012). Sleep and Sleep Disorders. http://www.cdc.gov/sleep/about sleep/how much sleep.htm

Christian, M. S., Evans, C., Hancock, N., Nyjkaer, C., \& Cade, J. (2013). Family Meals Can Help Children Reach Their 5 a Day: A Cross-Sectional Survey of Children's Dietary Intake from London Primary Schools. Journal of Epidemiology \& Community Health, 67, 332-338. http://dx.doi.org/10.1136/jech-2012-201604

Dreyer, C. A., \& Dreyer, A. S. (1973). Family Dinner Time as a Unique Behavior Habitat. Family Process, 12, 291-301. http://dx.doi.org/10.1111/j.1545-5300.1973.00291.x

Evers, C. (1997). Empower Children to Develop Healthful Eating Habits. Journal of the American Dietetic Association, 97, S116. http://dx.doi.org/10.1016/S0002-8223(97)00742-6

Feiring, C., \& Lewis, M. (1987). The Ecology of Some Middle Class Families at Dinner. International Journal of Behavioral Development, 10, 377-390. http://dx.doi.org/10.1177/016502548701000307

Fiese, B. H., Hammons, A., \& Grigsby-Toussaint, D. (2012). Family Mealtimes: A Contextual Approach to Understanding Childhood Obesity. Economics and Human Biology Journal, 10, 365-374. http://dx.doi.org/10.1016/j.ehb.2012.04.004

Fisher, J. O., \& Birch, L. L. (2002). Eating in the Absence of Hunger and Overweight in Girls from 5 to 7 y of Age. American Journal of Clinical Nutrition, 76, 226-231.

Fulkerson, J. A., Larson, N., Horning, M., \& Neumark-Sztainer, D. (2014). A Review of the Associations between Family or Shared Meal Frequency and Dietary and Weight Status Outcomes across the Lifespan. Journal of Nutrition Education and Behavior, 46, 2-19. http://dx.doi.org/10.1016/j.jneb.2013.07.012

Hammons, A. J., \& Fiese, B. H. (2011). Is Frequency of Shared Family Meals Related to the Nutritional Health of Children and Adolescents? Pediatrics, 127, 1565-1574. http://dx.doi.org/10.1542/peds.2010-1440

Hill, C., Llewellyn, C. H., Saxton, J., Webber, L., Semmler, C., Carnell, S., van Jaarsveld, C. H. M., Boniface, D., \& Wardle, J. (2008). Adiposity and 'Eating in the Absence of Hunger' in Children. International Journal of Obesity, 32, 1499-1505. http://dx.doi.org/10.1038/ijo.2008.113

Hughes, S. O., Anderson, C. B., Power, T. G., Micheli, N., Jaramillo, S., \& Nicklas, T. A. (2006). Measuring Feeding in Low-Income African-American and Hispanic Parents. Appetite, 4, 215-223. http://dx.doi.org/10.1089/bar.2006.9991

Hughes, S. O., Shewchuck, R. M., Baslin, M. L., Nicklas, T. A., \& Qu, H. (2008). Indulgent Feeding Style and Children’s Weight Status in Preschool. Journal of Developmental and Behavioral Pediatrics, 29, 403-410.

http://dx.doi.org/10.1097/DBP.0b013e318182a976 
Jansen, P. W., Roza, S. J., Jaddoe, V. W., Mackenbach, J. D., Raat, H., Hofman, A., Verhulst, F. C., \& Tiemeier, H. (2012). Children's Eating Behavior, Feeding Practices of Parents and Weight Problems in Early Childhood: Results from the Population-Based Generation R Study. International Journal of Behavior Nutrition, and Physical Activity, 9, 130-141. http://dx.doi.org/10.1186/1479-5868-9-130

Koszewski, W., Behrends, D., Nichols, M., Sehi, N., \& Jones, G. (2011). Patterns of Family Meals and Food and Nutrition Intake in Limited Resource Families. Family and Consumer Sciences Research Journal, 39, 431-441.

Liberatos, P., Link, B. G., \& Kelsey, J. L. (1988). The Measurement of Social Class in Epidemiology. Epidemiologic Reviews, 10, 87-121.

Martin-Biggers, J., Spaccarotell, K., Berhaupt-Glickstein, A., Hongu, N., Worobey, J., \& Byrd-Bredbenner, C. (2014). Come and Get It! A Discussion of Family Mealtime Literature and Factors Affecting Obesity Risk. Advances in Nutrition, 5, 235-247. http://dx.doi.org/10.3945/an.113.005116

McIntosh, W. A. (1999). The Family Meal and Its Significance in Global Times. In R. Grew (Ed.), Food in Global History (pp. 217-239). Boulder, CO: Westview Press.

Moray, J., Fu, A., Brill, K., \& Mayoral, M. S. (2007). Viewing Television While Eating Impairs the Ability to Accurately Estimate Total Amount of Food Consumed. Bariatric Nursing and Surgical Patient Care, 2, 71-76. http://dx.doi.org/10.1089/bar.2006.9991

Murphy, J. M. (2007). Breakfast and Learning: An Updated Review. Journal of Current Nutrition and Food Science, 1, 3-36. http://dx.doi.org/10.2174/1573401310703010003

Neumark-Sztainer, D., Hannan, P., Story, M., Croll, J., \& Perry, C. (2003). Family Meal Patterns: Associations with Sociodemographic Characteristics and Improved Intake among Adolescents. Journal of the American Dietetic Association, 103, 317-322. http://dx.doi.org/10.1016/S0002-8223(02)00084-6

New Jersey Head Start (2014). http://www.benefits.gov/benefits/benefit-details/1926.

Patrick, H., Hennessy, E., McSpadden, K., \& Oh, A. (2013). Parenting Styles and Practices in Children’s Obesogenic Behaviors: Scientific Gaps and Future Research Directions. Childhood Obesity, 9, S-73-S-86.

Patrick, H., Nicklas, T. A., Hughes, S. O., \& Morales, M. (2005). The Benefits of Authoritative Feeding Style; Caregiver Feeding Styles and Children's Food Consumption Patterns. Appetite, 44, 243-249. http://dx.doi.org/10.1016/j.appet.2002.07.001

Powers, S. W., Chamberlin, L. A., van Schaick, K. B., Sherman, S. N., \& Whitaker, R. C. (2006). Maternal Feeding Strategies, Child Eating Behaviors, and Child BMI in Low-Income African-American Preschoolers. Obesity, 14, 2026-2033. http://dx.doi.org/10.1038/oby.2006.237

Skala, K., Chuang, R. J., Evans, A., Hedberg, A., Dave, J., \& Sharma, S. (2012). Ethnic Differences in the Home Food Environment and Parental Food Practices among Families of Low-Income Hispanic and African-American Preschoolers. Journal of Immigrant Minority Health, 14, 1014-1022. http://dx.doi.org/10.1007/s10903-012-9575-9

Spruijt-Metz, D., Lindquist, C. H., Birch, L. L., Fisher, J. O., \& Goran, M. I. (2002). Relation between Mothers' Child-Feeding Practices and Children's Adiposity. American Journal of Clinical Nutrition, 75, 581-586.

Story, M., Kaphingst, K. M., Robinson-O’Brien, R., \& Glanz, K. (2007) Creating Healthy Food and Eating Environments: Policy and Environmental Approaches. Annual Review of Public Health, 29, 253-272.

http://dx.doi.org/10.1146/annurev.publhealth.29.020907.090926

Taheri, S. (2006). The Link between Short Sleep Duration and Obesity: We Should Recommend More Sleep to Prevent Obesity. Archives of Diseases in Childhood, 91, 881-884. http://dx.doi.org/10.1136/adc.2005.093013

Taveras, E. M., Rifas-Shiman, S. L., Berkey, C. S., Rockett, H. R. H., Field, A. E., Frazier, A. L., Colditz, G. A., \& Gillman, M. W. (2005). Family Dinner and Adolescent Overweight. Obesity Research, 13, 900-906. http://dx.doi.org/10.1038/oby.2005.104

USDA (2011). About Us—MyPlate. United States Department of Agriculture. http://www.choosemyplate.gov/about.html

Varela, R. E., Vernberg, E. M., Sanchez-Sosa, J. J., Riveros, A., Mitchell, M., \& Mashunkashey, J. (2004). Parenting Style of Mexican, Mexican-American, and Caucasian-Non-Hispanic Families: Social Context and Cultural Influences. Journal of Family Psychology, 18, 651-657. http://dx.doi.org/10.1037/0893-3200.18.4.651

Worobey, J., Borelli, A., Espinosa, C., \& Worobey, H. S. (2013). Feeding Practices of Mothers from Varied Income and Racial/ Ethnic Groups. Early Child Development and Care, 183, 1661-1668. http://dx.doi.org/10.1080/03004430.2012.752735 